\title{
Effects of green tea, calcium hydroxide and chlorhexidine on chemical structure and tooth discoloration
}

\author{
Mehdi Vatanpour, ${ }_{1}^{1}$ Sara Esmaili, ${ }^{2 *}$ Payman Mehrvarz Dar ${ }^{3}$ and Hamed Zahedi Pour ${ }^{4}$ \\ ${ }^{1}$ Assistant Professor, Department of Endodontics, Dental Branch, Islamic Azad University, Tehran, Iran \\ ${ }^{2}$ Department of Endodontics, Dental Branch, Islamic Azad University, Tehran, Iran \\ ${ }^{3}$ Associated professor, Department of Endodontics, Dental Branch, Islamic Azad University, Tehran, Iran \\ ${ }^{4}$ Craniomaxillofacial Research Center, Tehran University of Medical Sciences
}

\begin{abstract}
Natural and herbal substances are increasingly playing a significant role and gradually replacing chemical medicaments. Green tea has benefits such as lower price, low toxicity and its anti-inflammatory properties is. The aim of the present study was to study the effects of green tea, calcium hydroxide and chlorhexidine on chemical structure changes and tooth discoloration. 60 single-rooted premolar teeth with no caries or filling were collected and randomly divided into 4 experimental groups $(n=15)$. Group 1, was kept as control, group 2-4 treated with green tea, calcium hydroxide and chlorhexidine, respectively. Each tooth was decoronated horizontally from $3 \mathrm{~mm}$ below CEJ. The crowns were used in part of the research dealing with tooth discolorations and roots for the part addressing chemical structure changes. The samples were placed in distilled water and exposed to indirect sunlight to simulate natural conditions until the end of experiment. The analysis of the tooth colors was done by VITA-easy shade spectrophotometer immediately on days 1, 7, 30 and 90 after placement. The infra-red spectra reflecting chemical structure of each sample was drawn by ATR-FTIR.Tooth discoloration on first day and third month showed no significant difference between all study groups $(\mathrm{P}>0.05)$. Significant difference observed between positive control and green tea groups after 7 days $(\mathrm{P}<0.05)$. A significant differences detected between positive control and the rest of groups after 30 days $(\mathrm{P}<0.05)$. In chemical structure change analysis significant difference was observed between green tea and chlorhexidine with control group $(\mathrm{P}<0.05)$. These results suggested short term administration of these materials has no side effect on teeth discoloration.
\end{abstract}

KEY WORDS: CALCIUM HYDROXIDE, CHLORHEXIDINE, GREEN TEA, TOOTH DISCOLORATION

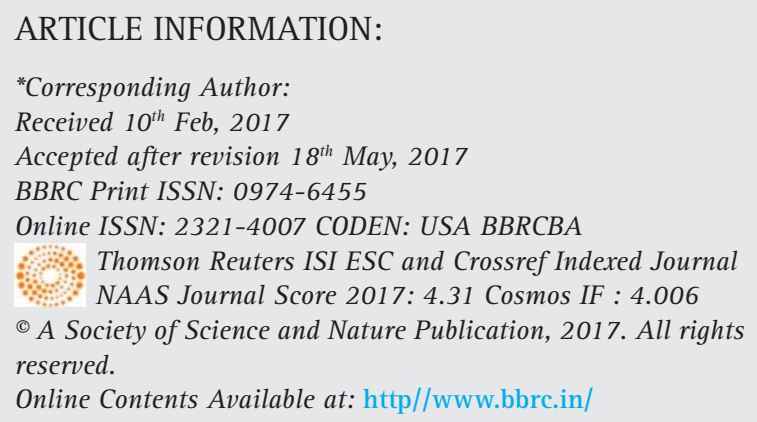




\section{INTRODUCTION}

Restoration of smile is one of the most challenging and esthetically satisfying services a prosthodontist can render to a patient. Dental porcelain is used extensively as a restorative material in a variety of dental restorations, including all ceramic restorations, metal ceramic crowns, and fixed partial dentures because of because of its esthetic properties, durability, and biocompatibility (Jain et al. 2013). Tooth discolouration creates a range of aesthetic problems, and considerable amounts of time and money are invested in attempts to improve the appearance of discoloured teeth. Discolouration is a more significant factor for many people in achieving an aesthetic smile than restoring their normal alignment within the arch (Sulieman 2008). Therefore, it is important for dental professionals to have a thorough knowledge and understanding of the etiology and clinical features of tooth discolouration to select the most appropriate treatment for each case (Ahmed and Abbott, 2012).

Any changes of tooth structure are likely to cause an alteration in outward appearance of the tooth caused by changes of light transmitting and reflecting properties (Mishra and Mishra, 2013). Some discolorations are located on the outer surface of the tooth structure, others are caused by stain taken up by the enamel or dentin, and some occur during tooth development and result in an alteration of the light transmitting properties of the tooth structures (Nugalaet al. 2012). The exogenous staining may occur due to the ability of the restoration to adsorb or absorb stains in the oral cavity which may be potentialized by surface conditions such as roughness. Studies have been undertaken to evaluate the color stability of composite restorations and it has been concluded that composite resins are unable to retain the color they possess at the time of insertion (Ghahramanloo et al. 2008). Crown discoloration related to endodontic filling materials is associated with the material time to contact the tooth structure, as well as the potential chromogenic materials used in the treatment (Xavier et al. 2017).

There are many disinfectant solutions, with particular advantages and disadvantages (Gomes et al. 2008). For example, sodium hypochlorite $(\mathrm{NaOCl})$ shows antimicrobial activity against a wide range of micro-organisms and relatively good tissue solubility. However this irrigant has several disadvantages such as cytotoxicity, tissue burning, bad taste and odor and discoloration of patient's clothes (Razmi et al. 2016). The materials commonly used in Endodontics for primary teeth are zinc oxide eugenol, iodoform pastes, and calcium hydroxide pastes (Krastl et al. 2013). In a study Xavier et al. (2017) studied effect of zinc oxide, eugenol cement, Vitapex and calcium hydroxide thickened with zinc oxide on bovine tooth discoloration. Based on their report zinc oxide and eugenol had higher discoloration. VivacquaGomes et al. (2002) observed a dark brown precipitate when $\mathrm{NaOCl}$ was combined with chlorhexidine gel. Other authors have reported the same type of discolouration when $\mathrm{NaOCl}$ has been used with chlorhexidine solutions (Bui et al. 2008, Akisue et al. 2010, Nassar et al. 2011).

Plants have always been common sources of medical agents. Antimicrobial, antifungal and anticancer effects of many plants have been the subject of many studies (Shakouie et al. 2014). In dentistry, herbal medicines have been used as anti-inflammatory, analgesic and antibacterial agents for many years (Shakouie et al. 2014). Vinothkumar et al. (2013) have examined the antibacterial effects of several herbal extracts including Aloe barbadensis, Myristica frangrans, Terminalia chebula, Curcuma longa and Azadaricta indica as endodontic irrigants. Green tea is obtained from the leaves of young camellia sinensis tree. Its antibacterial activity is due to inhibition of the DNA gyrase bacterial enzymes by binding to the ATP binding sites of the ATPB subunit. Green tea has antibacterial activity against E. faecalis and it also has been known as a chelating agent (Naderi et al. 2011).

Despite previous researches on anti-bactericidal activity of the green tea, there is scarce information on its tooth discoloration activity. So, the aim of the current study was to determine effects of green tea, calcium hydroxide and chlorhexidine on chemical structure and tooth discoloration.

\section{MATERIALS AND METHODS}

This in vivo study is performed on 60 single-rooted premolar teeth with no caries or filling were collected and randomly divided into 4 experimental groups $(n=15)$. All the samples were extracted for the purpose of orthodontic treatments approximately a month before the study. Each tooth was decoronated horizontally from $3 \mathrm{~mm}$ below CEJ. The crowns were used in part of the research dealing with tooth discolorations and roots for the part addressing chemical structure changes. After cleaning the root canal section and pulp chamber with ultrasonic and $\mathrm{NaOCl}$ (5.25\%), EDTA (17\%) was applied to remove smear layer for one minute, then the canals rinsed with $\mathrm{NaOCl}$. The medicaments got placed in pulp chambers and the apical opening of the canals was sealed with glass ionomer. Premolar teeth randomly allocated into 4 experimental groups: group 1 , kept as control, group 2-4 treated with green tea, calcium hydroxide and chlorhexidine, respectively. The samples were placed in distilled water and exposed to indirect sunlight to simulate natural conditions until the end of experiment. The 
phosphate/amid ratio between samples was determined at day 1, 7, 30 and 90.

The analysis of the tooth colors was done by VITAeasy shade spectrophotometer at day 1, 7, 30 and 90. In order to assimilate the samples and reach pulpal surface required for the chemical structure analysis, each tooth was sectioned both in vertical and horizontal directions by DEZZ diamond disc. Each root provided 1 sample per group (4 samples in total). The infra-red spectra reflecting chemical structure of each sample was drawn by ATR-FTIR. Each sample was located in its relevant well filled with medicaments and placed in incubator. Data is analyzed by one-way analysis of variance (ANOVA) using SPSS 16.0 for Windows (SPSS, Inc., Chicago, IL, USA). For treatment showing main effect by ANOVA, means compared by Mann-Whitney (parameteric) and Kruskal-Wallis (nonparametric) tests. $\mathrm{P}<0.05$ was considered as significant differences between treatments.

\section{RESULTS AND DISCUSSION}

As seen in the table 1, no significant difference observed on color change on first day $(P>0.05)$. A significant difference detected between green tea and positive control with the other groups after 7 days $(\mathrm{P}<0.05)$. No significant difference detected between positive group compared to the other groups on day $30(\mathrm{P}>0.05)$.

As seen in figure 2, no significant change observed on the $\mathrm{AE}$ of the color change on day 1 and 90 between the groups $(\mathrm{P}>0.05)$. Significant difference detected

\begin{tabular}{|c|c|c|c|}
\hline Groups & Time (day) & Mean \pm Sd & C.V \\
\hline \multirow{4}{*}{ Control } & 1 & $1.00 \pm 0.23$ & 0.23 \\
\hline & 7 & $1.53 \pm 0.27$ & 0.17 \\
\hline & 30 & $3.79 \pm 0.48$ & 0.12 \\
\hline & 90 & $4.80 \pm 6.71$ & 1.39 \\
\hline \multirow{4}{*}{ calcium hydroxide } & 1 & $1.36 \pm 1.64$ & 1.20 \\
\hline & 7 & $1.84 \pm 1.62$ & 0.88 \\
\hline & 30 & $1.42 \pm 1.65$ & 1.16 \\
\hline & 90 & $2.50 \pm 5.88$ & 2.35 \\
\hline \multirow{4}{*}{ Chlorhexidine } & 1 & $0.54 \pm 0.61$ & 1.12 \\
\hline & 7 & $2.01 \pm 1.58$ & 0.78 \\
\hline & 30 & $2.44 \pm 1.96$ & 0.80 \\
\hline & 90 & $2.50 \pm 2.98$ & 1.19 \\
\hline \multirow{4}{*}{ Green tea } & 1 & $0.94 \pm 0.58$ & 0.61 \\
\hline & 7 & $0.91 \pm 0.50$ & 0.54 \\
\hline & 30 & $0.51 \pm 0.16$ & 0.31 \\
\hline & 90 & $0.35 \pm 0.37$ & 1.05 \\
\hline
\end{tabular}

between positive control and greet tea compared to the other groups on days 7 and $30(\mathrm{P}<0.05)$

Tooth discoloration is a possible side effect of endodontic treatment of anterior teeth (Krastl et al. 2013). Hemorrhage inside the pulp cavity, residual pulpal tissue as well as materials used during root canal treatment are the most usual causes for discoloration (Ahmed et al. 2012). In addition obturating materials, intracanal medicaments and temporary filling materials may cause also of internal tooth staining (Lenherr et al. 2012). As far as the intracanal medicaments concerns, their role in the success of the endodontic treatment is important, since they maintain the root canals disinfected for the time interval between instrumentation and final root canal obturation (Silveira et al. 2011). Calcium hydroxide plays an important role in endodontics due to its ability to induce hard tissue formation, its antibacterial effect and its ability to act as a physical barrier to prevent root canal reinfection (Mohammadi and Dummer, 2011).

These properties derive from its high $\mathrm{pH}$ (up to 12.5), which neutralises lactic acid from the osteoclasts, thus preventing a dissolution of the mineral components of dentin. Moreover, it could also activate alkaline phosphatases which play an important role in hard tissue formation (Mohammadi and Dummer, 2011). One of the most important antimicrobial agents in dentistry is chlorexidine. The most significant properties that justify the use of chlorexidine as an intracanal medicament are its antimicrobial activity against Grampositive and Gramnegative microorganisms, as well as its residual antimicrobial ability on the dentin surface after remaining for at least one week within the root canal (substantivity) (Mohammadi and Abbott, 2009).

Moreover, chlorexidine is effective against bacteria that are resistant to $\mathrm{Ca}(\mathrm{OH})_{2}$ and mainly E. faecalis; this property justifies the use of chlorexidine in retreatments, where such bacteria are usually found. However, clinical studies have recorded tooth staining by chlorexidine, especially when it is used as a mouthrinse for periodontal treatment (Gomes et al. 2013). The most possible staining mechanisms of tooth discolorations due to chlorexidine application seem to be non-enzymatic browning (Maillard reactions) and formation of pigmented black metal sulfides (Gomes et al. 2013).

Nevertheless, the corresponding phenomenon has not been investigated in cases when chlorexidine is used for endodontic purposes. On the contrary, the staining potential of $\mathrm{Ca}(\mathrm{OH})$, has not been clearly defined, as its discoloration ability may depend on its chemical composition(pure $\mathrm{Ca}(\mathrm{OH})$, powder, or commercial $\mathrm{Ca}(\mathrm{OH})_{2}$ pastes whose some contents may be able to discolor teeth). Nevertheless, some latest studies have concluded that $\mathrm{Ca}(\mathrm{OH})_{2}$ has indeed a discoloration poten- 

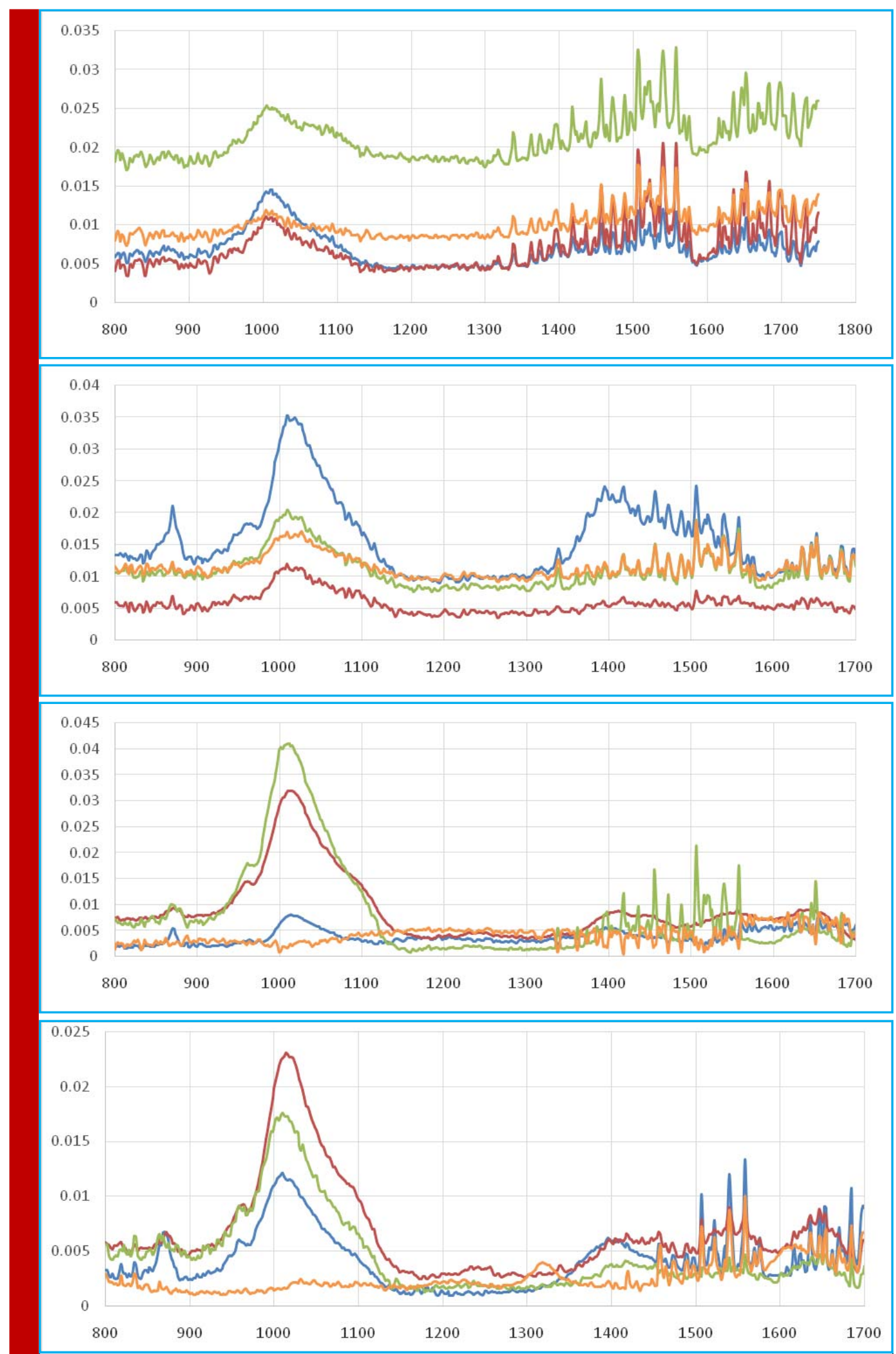

FIGURE 1. The ATR-FTIR results of the samples. Green: control, orange: green tea, blue: calcium hydroxide, Red: chlorhexidine; Figures from up to down: days 1, 7, 30 and 90. 


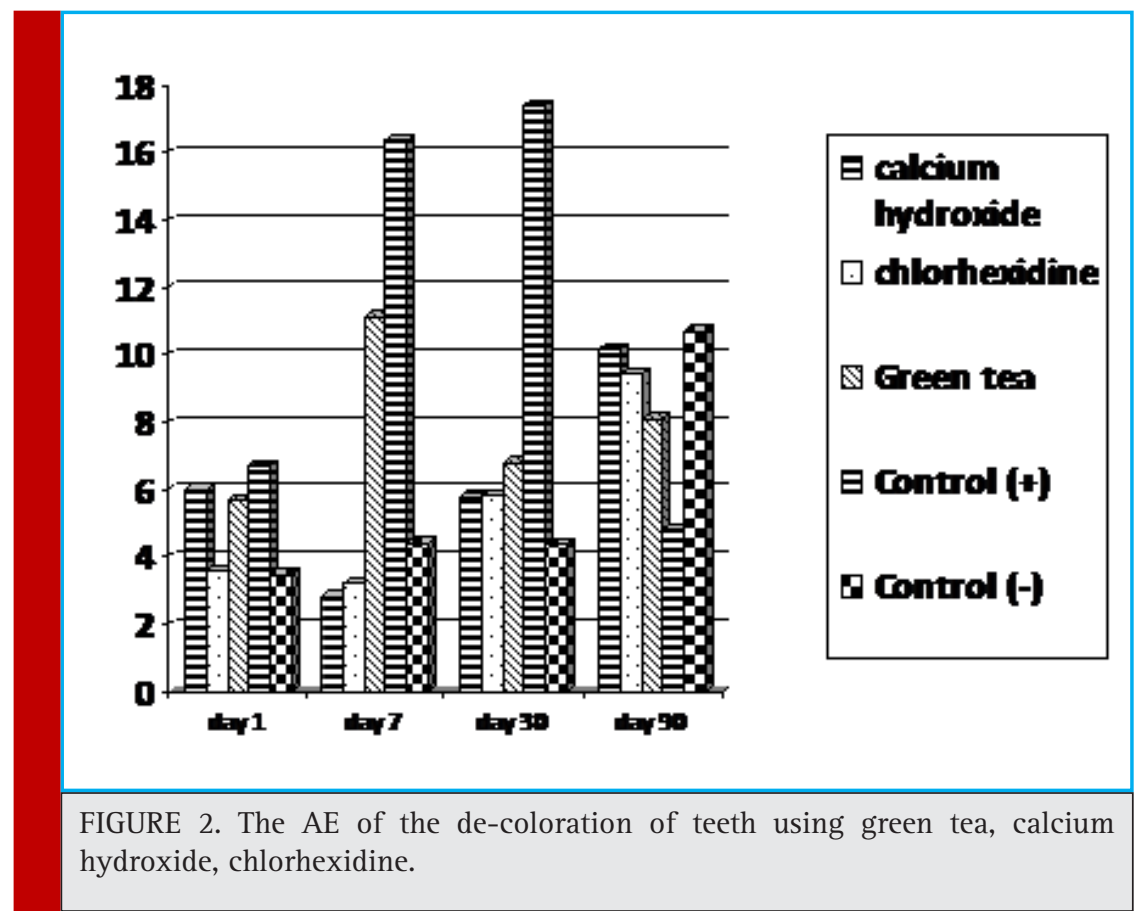

tial, which might not have been extensively taken into account up to date (Krastl et al. 2013). The exact staining mechanism of $\mathrm{Ca}(\mathrm{OH})_{2}$ is not clearly known; it has been implied that it is more likely due to any additional components, i.e. bismuth carbonate, that usually exist in many commercially-prepared $\mathrm{Ca}(\mathrm{OH})_{2}$ pastes, while as regards pure $\mathrm{Ca}(\mathrm{OH})_{2}$ powder, there has not been a convincing explanation.

It is a common knowledge that many intracanal medicaments may result in tooth discoloration, but as regards $\mathrm{Ca}(\mathrm{OH}) 2$, its possible impact on color alterations remains unclear. Day et al. (2011) recorded discoloration of replanted teeth after avulsion, which had been treated with $\mathrm{Ca}(\mathrm{OH}) 2$. The influence of $\mathrm{Ca}(\mathrm{OH}) 2$ on discoloration may be more severe in teeth with vital pulpal tissue, possibly because of the existence of erythrocytes which contribute to color changes after $\mathrm{Ca}(\mathrm{OH}) 2$-induced haemolysis (Addy and Moran, 1995). The calcium hydroxide dressings varied in their discoloration ability. Pure calcium hydroxide and Ultracal XS did not show any discoloration or difference to the negative controls at any time. Interestingly, the Apex- Cal specimens showed an increase in their DE values in the second half of the observation period. The difference to all the other calcium hydroxide materials was statistically significant after 12 months (Lenherr et al. 2012).

Moghbel et al. (2011) investigated the antibacterial effect of green tea at concentrations of $1 \%, 0.2 \%$ and $0.5 \%$ compared with chlorhexidine $0.2 \%$. According to the obtained results, through an increase in the concentration of green tea, the effect of this extract on Strep- tococcus mutans and Staphylococcus aureus increases, so that $1 \%$ concentration of tannin in green tea extract with chlorhexidine has a similar effect in the reduction of mouth aerobic bacteria. Therefore, instead of using chemical mouthwashes such as chlorhexidine, this herbal mouthwash is recommended especially for children and pregnant women. Although the bacterial strains used in their study are not identical to this one, in both studies, with an increase in concentration of green tea extract, their antimicrobial activity is also increased (Moghbel et al. 2012).

Neyestani et al. (2007) investigated the effect of green tea in comparison with black tea on Streptococcus pyogenes strains; they also stated that an increase in the concentration of green tea extract increases its effect, although in their research the studied pathogens were different from this study. Also according to their results, the effect of green tea in similar concentrations was more than that of black tea on micro-organisms. In conclusion, these results suggested short term administration of these materials has no side effect on teeth discoloration.

\section{REFERENCES}

Addy, M. and Moran, J. (1995) Mechanisms of Stain Formation on Teeth, in Particular Associated with Metal Ions and Antiseptics. Advances in Dental Research, 9, 450-456.

Ahmed HMA, Abbott PV. Discolouration potential of endodontic procedures and materials: a review. International Endodontic Journal, 45, 883-897, 2012. 
Ahmed, H.M.A. and Abbott, P.V. (2012) Discoloration Potential of Endodontic Procedures and Materials: A Review. International Endodontic Journal, 45, 883-897.

Akisue E, Tomita VS, Gavini G, Poli de Figueiredo JA (2010) Effect of the combination of sodium hypochlorite and chlorhexidine on dentinal permeability and scanning electron microscopy precipitate observation. Journal of Endodontics 36, 847-50.

Bui TB, Baumgartner JC, Mitchell JC (2008) Evaluation of the interaction between sodium hypochlorite and chlorhexidine gluconate and its effect on root dentin. Journal of Endodontics $34,181-5$.

Day, P.F., Duggal, M.S., High, A.S., Robertson, A., Gregg, T.A., Ashley, P.F., et al. (2011) Discoloration of Teeth after Avulsion and Replantation: Results from a Multicenter Randomized Controlled Trial. Journal of Endodontics, 37, 1052-1057.

Ghahramanloo A, Madani SA, Sohrabi K, Sabzevari S. An evaluation of color stability of reinforced composite resin compared with dental porcelain in commonly consumed beverages. J Can Dent Assoc2008;136:673-80.

Gomes BP, Pinheiro ET, Jacinto RC, Zaia AA, Ferraz CC, SouzaFilho FJ. Microbial analysis of canals of root-filled teeth with periapical lesions using polymerase chain reaction. J Endod. 2008;34(5):537-40.

Gomes, B.P., Vianna, M.E., Zaia, A.A., Almeida, J.F., SouzaFilho, F.J. and Ferraz, C.C. (2013) Chlorexidine in Endodontics. Brazilian Dental Journal, 24, 89-102.

Jain C, Bhargava A, Gupta S, Rath R, Nagpal A, Kumar P. Spectrophotometric evaluation of the color changes of different feldspathic porcelains after exposure to commonly consumed beverages. Eur J Dent 2013;7:172-80.

Krastl G., Allgayer N., Lenherr P., Filippi A., Taneja P., Weiger R. 2013. Tooth discoloration induced by endodontic materials: a literature review," Dental Traumatology, vol. 29, no. 1, pp. 2-7.

Krastl, G., Allgayer, N., Lenherr, P., Filippi, A., Taneja, P. and Weiger, R. (2013) Tooth Discoloration Induced by Endodontic Materials: A Literature Review. Dental Traumatology, 29, 2-7.

Lenherr, P., Allgayer, N., Weiger, R., Filippi, A., Attin, T. and Krastl, G. (2012) Tooth Discoloration Induced by Endodontic Materials: A Laboratory Study. International Endodontic Journal, 45, 942-949.

Mishra S, Mishra M. B. Tobacco: 2013. Its historical, cultural, oral, and periodontal health association. Journal of International Society of Preventive \&t Community Dentistry. 3(1): 12-18.

Moghbel A, Farjzadeh A, Aghel N, Agheli H, Raisi N. Evaluation of the effect of green tea extract on mouth bacterial activity in the presence of propylene glycol. Jundishapur J Nat Pharm Prod. 2012;7(2):56-60.

Moghbel A, Farjzadeh A, Aghel N, Agheli H, Raisi N. The Effect of Green Tea on Prevention of Mouth Bacterial Infec- tion, Halitosis, and Plaque Formation on Teeth. Iran J Toxicol. 2011;5(14):502-15.

Mohammadi, Z. and Abbott, P.V. (2009) The Properties and Applications of Chlorexidine in Endodontics. International Endodontic Journal, 42, 288-302.

Mohammadi, Z. and Dummer, P.M.H. (2011) Properties and Applications of Calcium Hydroxide in Endodontics and Dental Traumatology. International Endodontic Journal, 44, 697-730.

Naderi NJ, Niakan M, Kharazi Fard MJ, Zardi S. Antibacterial activity of Iranian green and black tea on streptococcus mutans: an in vitro study. J Dent (Tehran). 2011;8(2):55-9.

Nassar M, Awawdeh L, Jamleh A, Sadr A, Tagami J (2011) Adhesion of Epiphany self-etch sealer to dentin treated with intracanal irrigating solutions. Journal of Endodontics 37, 228-30.

Neyestani T, Khalaji N. Inhibitory effects of black tea (Camellia sinensis) extractsonStreptococcus pyogenes: Acomparison between black and green teas in vitro. Iran J Nut Sci Food Technol. 2007;2(1):41-7.

Nugala B, Namasi A, Krishna P. Role of green tea as an antioxidant in periodontal disease: The Asian paradox. Journal of Indian Society of Periodontology 2012;16(3):313-316

Razmi H, Bolhari B, Dashti NK, Fazlyab M. The Effect of Canal Dryness on Bond Strength of Bioceramic and Epoxy-resin Sealers after Irrigation with Sodium Hypochlorite or Chlorhexidine. Iranian endodontic journal. 2016;11(2):129.

Shakouie S, Eskandarinezhad M, Gasemi N, Milani AS, Samiei M, Golizadeh S. An in vitro comparison of the antibacterial efficacy of triphala with different concentrations of sodium hypochlorite. Iranian endodontic journal. 2014;9(4):287-9.

Silveira, C.F.M., Cunha, R.S., Fontana, C.E., de Martin, A.S., Gomes, B.P.F.A., Lopes Motta, R.H. and Bueno, C.E.S. (2011) Assessment of the Antibacterial Activity of $\mathrm{Ca}(\mathrm{OH}) 2$ Combined with Chlorexidine Paste and Other Intracanal Medications against Bacterial Pathogens. European Journal of Dentistry, 5, 1-7.

Sulieman MA (2008) An overview of tooth-bleaching techniques: chemistry, safety and efficacy. Periodontology 2000 48, 148-69.

Vinothkumar TS, Rubin MI, Balaji L, Kandaswamy D. In vitro evaluation of five different herbal extracts as an antimicrobial endodontic irrigant using real time quantitative polymerase chain reaction. J Conserv Dent. 2013;16(2):167-70.

Vivacqua-Gomes N, Ferraz CC, Gomes BP, Zaia AA, Teixeira FB, Souza-Filho FJ (2002) Influence of irrigants on the coronal microleakage of laterally condensed gutta-percha root fillings. International Endodontic Journal 35, 791-5.

Xavier SR, Pilownic KJ, Gastmann AH, Echeverria MS, Romano AR, Pappen FG. Bovine tooth discoloration induced by endodontic filling materials for primary teeth. International Journal of Dentistry Volume 2017, Article ID 7401962, 5 pages https:// doi.org/10.1155/2017/7401962. 